\title{
PENGARUH TERAPI MUROTTAL AL-QUR'AN TERHADAP TINGKAT KECEMASAN IBU MENGHADAPI PERSALINAN DI RUMAH SAKIT SITI KHADIJAH III MAKASSAR
}

\begin{abstract}
ABSTRAK
Terapi murottal Al-Qur'an menjadi bagian dari terapi musik (karena murottal Al- Qur'an dapat diartikan sebagai rekaman suara Al-Qur'an yang dilagukan oleh seorang Qori' (pembaca AlQur'an). Murottal Al-Qur'an juga menjadi terapi spiritualitas karena membuat individu mengingat Allah SWT. Kepercayaan spiritual memainkan peranan penting dalam mengahadapi kecemasan persalinan. Beberapa penelitian telah menunjukkan pengurangan rasa nyeri dan penurunan kecemasan padapasien. Tujuan dalam penelitian ini adalah untuk mencari Pengaruh Terapi Murottal Al- Qur'an Terhadap Tingkat Kecemasan Ibu Menghadapi Persalinan di RSIA Siti Khadijah III Makassar. Metode Penelitian dilaksanakan pada bulan Mei 2018 di RSIA Siti Khadijah III Makassar. Jenis penelitian ini adalah pendekatan Quasy Eksperiment. Populasi dalam penelitian ini adalah seluruh ibu inpartu diperoleh sampel sebanyak 30 orang. Hasil penelitian menunjukkan bahwa dari 30 jumlah responden, berdasarkan pretest tingkat kecemasan kelompok perlakuan sebelum diberikan terapi murottal Al-Qur'an menunjukkan bahwa jumlah responden dengan kecemasan ringan sebesar 20,0\%, kecemasan tingkat sedang dan berat masing-masing sebesar 33,3\% dan 46,7\%. Berdasarkan postest tingkat kecemasan kelompok perlakuan setelah diberikan terapi murottal Al-Qur'an menunjukkan bahwa jumlah responden dengan kecemasan ringan sebesar 56,7\%, kecemasan sedang dan berat sebesar 36,7\% dan $6,7 \%$. Ada pengaruh pemberian terapi murottal Al-Qur'an terhadap tingkat kecemasan ibu hamil dengan nilai $p=0,000$ yang berarti Ho ditolak dan Ha diterima. Disimpulkan bahwa terapi dapat meningkatkan pelayanan dan keterampilan dalam menangani kasus-kasus seperti tingkat kecemasan dengan menggunakan teknik murottal Al -Qur'an.
\end{abstract}

Nurqalbi $^{1^{*}}$, Mudyawati Kamaruddin ${ }^{2}$

${ }^{1}$ Midwifery Program, University of Mega Rezky, Makassar, South Sulawesi, Indonesia

${ }^{2}$ Midwifery Academy, Tahirah Al Baeti, Bulukumba, South Sulawesi, Indonesia

*Corresponding author: Telp +6285242572256, email: nurqalbisr@gmail.com

Kata Kunci: Terapi, Murottal Al-Qur'an, Tingkat Kecemasan

\section{ABSTRACT}

Murottal Al-Qur'an therapy is part of music therapy (because murottal Al-Qur'an can be interpreted as a recording of the voice of the Qur'an which is questioned by a Qori '(reader of the Qur'an). Murottal Al-Qur' It is also a therapy of spirituality because it makes individuals remember Allah SWT. Spiritual belief plays an important role in dealing with labor anxiety. Several studies have shown a reduction in pain and decreased anxiety in patients. The purpose of this study was to look for the Effects of Murottal Al-Qur'an Therapy on the Anxiety Level of Mothers Facing Labor in Siti Khadijah III Makassar Hospital. The study was conducted in May 2018 at Siti Khadijah III Makassar Hospital. This type of research is the Quasy Experiment approach. The population in this study was all mothers in part obtained a sample of 30 people. The results showed that from 30 respondents, based on the pretest level of anxiety the treatment group before being given murottal Al-Qur'an therapy showed that the number of respondents with mild anxiety was 6 people (20.0\%), moderate anxiety was 10 people $(33.3 \%)$ and weighs 14 people (46.7\%). Based on the posttest level of anxiety the treatment group before being given murottal Al-Qur'an therapy showed that the number of respondents with mild anxiety was 17 people (56.7\%), moderate anxiety as many as 11 people (36.7\%) and severe as many as 2 people (6.7\%). There is the effect of giving Murottal Al-Qur'an therapy to the anxiety level of pregnant women with a value of $p=0,000$ which means that Ho is rejected and Ha is accepted. Can 
improve service and skills in handling cases such as anxiety levels using the Murottal Al Qur'an technique

Keywords: Murottal Al-Qur'an, Therapy, Anxiety Level

\section{PENDAHULUAN}

Rencana Strategi Nasional Making Prenancy Safe (MPS) Indonesia disebutkan dalam rencana kontek pembangunan kesehatan Indonesia adalah kehamilan dan persalinan di Indonesia berlangsung aman, serta bayi dilahirkan hidup dan sehat. Misi MPS adalah menurunkan Tingkat kesakitan dan kematian maternal juga neonatal melalui kegiatan yang mempromosikan kesehatan ibu dan bayi baru lahir. ${ }^{1}$

Pemeriksaan rutin pra-kelahiran sangat penting agar yang dialami ibu hamil dapat ditemukan masalah sedini mungkin dan dapat ditanggulangi, sebelum berkembang menjadi membahayakan ibu maupun bayinya. Sebaiknya ibu hamil menjalani pemeriksaan kesehatan paling sedikit empat kali selama hamil yaitu satu kali pada Trimester I usia kehamilan 0-14 minggu, satu kali pada Trimester II usia kehamilan sebelum 28 minggu dan dua kali pada Trimester III usia kehamilan 28-36 minggu dan setelah 36 minggu. ${ }^{2}$

Masa kehamilan adalah sebuah impian yang sangat dinanti dan diharapkan oleh pasangan suami dan istri. Pada umumnya kehamilan berkembang dengan normal dan menghasilkan kelahiran bayi sehat cukup bulan melalui jalan lahir. Namun demikian tidak semua hasil kehamilan dan persalinan akan menggembirakan seorang suami, ibu dan bayi lahir sehat, tetapi ibu hamil bisa menghadapi kegawatan dengan derajat ringan sampai berat yang dapat memberikan bahaya terjadinya ketidaknyamanan, ketidakpuasan, kesakitan, kecacatan bahkan kematian bagi ibu hamil, risiko tinggi, maupun rendah yang mengalami komplikasi dalam persalinan. ${ }^{1}$ Banyak penelitian yangmenunjukkan keefektifan murottal Al-Qur'an untuk meningkatkan ketenangan. murottal AlQur'an mampu memacu sistem saraf parasimpatis yang mempunyai efek berlawanan dengan sistem saraf simpatis, sehingga terjadi keseimbnagn pada kedua sistem saraf autonom tersebut. Hal inilah yang menjadi prinsip dasar dari timbulnya respon relaksasi, yaitu terjadi keseimbangan antara sistem saraf simpatis dan sistem sarafparasimpatis.

Penelitian tentang murottal Al- Qur'an sebagai salah satu terapi spiritualitas yang dapat mempercepat penyembuhan dilakukan oleh Ahmad Al Qhadi direktur utama Islamic Medicine Institute for Education and Research di Florida, Amerika Serikat dalam konferensi tahunan ke XVII Ikatan Dokter Amerika, wilayah Missuori AS, melakukan hasil presentasi tentang hasil penelitiannya dengan tema pengaruh Al- Qur'an pada manusia dalam perspektif fisiologis dan psikologis. Hasil penelitian tersebut menunjukkan hasil positif bahwa mendengarkan ayat suci AlQur'an memiliki pengaruh yang sangat signifikan dalam menurunkan ketegangan urat saraf reflektif dan hasil ini tercatat dan terukur secara kuantitatif dan kualitatif oleh sebuah alat berbasis komputer. Penelitian oleh Widhowati dalam Andriana (2007) menjelaskan bahwa terapi murottal Al-Qur'an lebih efektif meningkatkan ketenangan dibandingkan dengan terapimusik.

Data bahwa jumlah persalinan pada tahun 2016 jumlah ibu bersalin sebanyak 1027 orang. Sedangkan tahun 2017 jumlah ibu bersalin sebanyak 1138 orang dan pada bulan Januari 2018 jumlah ibu bersalin sebanyak 58 orang (Rekam Medik,2018).

\section{METODOLOGI}

\section{Desain Penelitian}

Penelitian ini menggunakan pendekatan eksperimen yang bersifat kuantitatif. Yaitu dengan menggunakan penelitian Quasy Eksperiment tentang pengaruh pemberian terapi murottal Al- Qur'an terhadap kecemasan ibu menghadapi persalinan. Desain penelitian yang digunakan dalam penelitian ini adalah "Nonequivalent Control Group Design". Jenis penelitian menggunakan satu kelompok eksperimen dengan kelompok pembanding dengan diawali dengan sebuah tes awal (pretest) yang diberikan kepada kedua kelompok, kemudian diberi perlakuan 
(treatment). Penelitian kemudian diakhiri dengan sebuah tes akhir (posttest) yang diberikan kepada kedua kelompok. ${ }^{4,5}$

\section{HASIL DAN PEMBAHASAN HASIL}

Penelitian dilaksanakan pada bulan Mei 2018 di di RSIA Siti Khadijah III Makassar Tahun 2018. Jenis penelitian ini adalah pendekatan QuasyEksperiment. Populasi dalam penelitian ini adalah seluruh ibu inpartu diperoleh sampel sebanyak 30 orang.

\section{KarakteristikResponden}

Tabel 1 Distribusi Frekuensi Karakteristik Responden Berdasarkan Umur di RSIA Siti Khadijah III Makassar Tahun 2018

\begin{tabular}{ccc}
\hline Umur & Frekuensi & $\begin{array}{c}\text { Persentase } \\
(\%)\end{array}$ \\
\hline$<20$ Tahun & 6 & 20,0 \\
20 - 35 Tahun & 20 & 66,7 \\
36 - 40 Tahun & 4 & 13,3 \\
\hline Jumlah & 30 & 100,00 \\
\hline
\end{tabular}

Sumber : Data Primer 2018

Tabel 2 Distribusi Frekuensi Karakteristik Responden Berdasarkan Paritas di RSIA Siti Khadijah III Makassar Tahun 2018

\begin{tabular}{ccc}
\hline Paritas & Frekuensi & Persentase (\%) \\
\hline Primipara & 7 & 23,3 \\
Mutipara & 18 & 60,0 \\
Grandemultipara & 5 & 16,7 \\
\hline Jumlah & 30 & 100,00 \\
\hline
\end{tabular}

Sumber : Data Primer 2018

Tabel 3 Distribusi Frekuensi Karakteristik RespondenBerdasarkan Pendidikan di RSIA Siti Khadijah III Makassar Tahun 2018

\begin{tabular}{ccc}
\hline Pendidikan & Frekuensi & Persentase $(\%)$ \\
\hline SD & 2 & 6,7 \\
SMP & 11 & 36,7 \\
SMA & 14 & 46,6 \\
Perguruan Tinggi & 3 & 10,0 \\
\hline Jumlah & 30 & 100,0 \\
\hline
\end{tabular}

Sumber : Data Primer 2018
2. AnalisisUnivariat

Tabel 4 Distribusi Frekuensi Responden Berdasarkan Pretest Tingkat Kecemasan di RSIA Siti Khadijah III Makassar Tahun 2018

Pretest Tingkat Frekuensi Persentase (\%) Kecemasan

\begin{tabular}{ccc}
\hline Ringan & 6 & 20,0 \\
Sedang & 10 & 33,3 \\
Berat & 14 & 46,7 \\
\hline Total & 30 & 100,0 \\
\hline
\end{tabular}

Sumber: Data Primer 2018

Tabel 5 Distribusi Frekuensi Responden Berdasarkan Postest Tingkat Kecemasan di RSIA Siti Khadijah III Makassar Tahun 2018

\begin{tabular}{ccc}
\hline $\begin{array}{c}\text { Postest Tingkat } \\
\text { Kecemasan }\end{array}$ & Frekuensi & $\begin{array}{c}\text { Persentase } \\
(\%)\end{array}$ \\
\hline Ringan & 17 & 56,7 \\
Sedang & 11 & 36,7 \\
Berat & 2 & 6,7 \\
\hline Total & 30 & 100,0 \\
\hline
\end{tabular}

Sumber: Data Primer 2018

\section{AnalisisBivariat}

Tabel 6 Pengaruh Terapi Murottal Al-Qur'an Terhadap Tingkat Kecemasan Ibu Menghadapi Persalinan di RSIA Siti Khadijah III Makassar Tahun 2018

\begin{tabular}{|c|c|c|c|c|c|}
\hline \multirow{2}{*}{$\begin{array}{c}\text { Tingkat } \\
\text { Kecemasan }\end{array}$} & \multicolumn{2}{|c|}{ Sebelum } & \multicolumn{2}{|c|}{ Sesudah } & \multirow{2}{*}{ Nilai $p$} \\
\hline & $\mathrm{n}$ & $\%$ & $\mathrm{n}$ & $\%$ & \\
\hline Ringan & 6 & $\begin{array}{c}20, \\
0\end{array}$ & 17 & 56,7 & \multirow{4}{*}{0,000} \\
\hline Sedang & 10 & 33,3 & 11 & 36,7 & \\
\hline Berat & 14 & $\begin{array}{c}46 \\
7\end{array}$ & 2 & 6,7 & \\
\hline Total & 30 & 100,0 & 30 & 100,0 & \\
\hline
\end{tabular}

Sumber: Data Primer 2018

\section{PEMBAHASAN}

Hasil penelitian menunjukkan bahwa jumlah responden berdasarkan pretest tingkat kecemasan kelompok perlakuan sebelum diberikan terapi murottal Al-Qur'an menunjukkan bahwa berdasarkan pretesttingkat kecemasan kelompok perlakuan sebelum diberikan terapi murottal Al- Qur'an menunjukkan bahwa jumlah responden dengan kecemasan ringan sebanyak 6 orang $(20,0 \%)$, kecemasan sedang sebanyak 10 
orang $(33,3 \%)$ dan berat sebanyak orang $(46,7 \%)$.

berdasarkan postest tingkat kecemasan kelompok perlakuan sebelum diberikan terapi murottal Al-Qur'an menunjukkan bahwa jumlah responden dengan kecemasan ringan sebanyak 17 orang $(56,7 \%)$, kecemasan sedang sebanyak 11orang(36,7\%)dan berat sebanyak 2 orang $(6,7 \%)$.

Berdasarkan uji Wilcoxon Signed Rank Test kelompok perlakuan menunjukkan bahwa nilai $\mathrm{p}=0.000$ lebih kecil dari $\alpha=0,05$ sehingga Ha diterima, maka disimpulkan ada pengaruh pemberian terapi murottal AlQur'an terhadap tingkat kecemasan ibu hamil

Hasil penelitian diatas terdapat 6 orang yang mengalami kecemasan ringan sebelum terapi murottal karena kondisi ibu menjelang persalinan cukup baik dan sebelumnya pernah melakukan persalinan. Sedangkan terdapat 10 orang yang mengalami kecemasan sedang karena kondisi ibu cukup khawatir dengan yang dirasakan dan 14 orang yang mengalami kecemasan berat karena kondisi yang dirasakan oleh ibu cukup cemas karena baru pertama kali merasakan kehamilan dan persalinan. Sedangkan setelah dilakukan terapi murottal masih ada 2 orang yang mengalami kecemasan berat. Hal ini dikarenakan setelah diberikan terapi murottal Al- Qur'an pasien kembali dihadapkan pada kenyataan stresor yang akan dihadapinya, sehingga rasa cemas kembali meningkat dan hal ini yang dirasakan oleh 2 orang pasien. Sedangkan yang mengalami kecemasan sedang terdapat 11 orang karena ibu yang sebelumnya mengalami kecemasan berat berangsur baik sehingga masih mengalami cemas dalam kategori sedang dan 17 orang yang mengalami kecemasan ringan karena kondisi ibu yang berangsung membaik dan tidak terlalu merasakan cemas.

Secara klinis dapat dinyatakan partus dimulai bila timbul his dan pengeluaran lendir yang disertai darah (blody show). Lendir yang disertai darah ini berasal dari lendir kanalis servikalis karena serviks mulai membuka atau mendatar. Sedangkan darahnya berasal dari pembuluh- pembuluh kapiler yang berada di sekitar kanalis servikalis itu pecah karena pergeseranpergeseran ketika serviks membuka. ${ }^{6,7}$ Terapi murottal Al-Qur'an dapat diartikan sebagai rekaman suara Al-Qur'an yang dilagukan oleh Qori' (pembaca Al-Qur'an) Murottal AlQur'an merupakan salah satu musik yang memiliki pengaruh positif bagi pendengarnya. Terapi murottal Al- Qur'an adalah terapi bacaan Al-Qur'an yang merupakan terapi religidimana seseorang dibacakan ayat-ayat Al- Qur'an selama beberapa menit atau jam sehingga memberikan dampak positif bagi tubuh seseorang

Hasil penelitian ini sejalan dengan yang dilakukan oleh Mudiana (2013) di RS. Kartadi Semarang dengan judul pengaruh terapi murottal dengan tingkat kecemasan menunjukkan dari 42 orang, dominan mengalami kecemasan ringan setelah diberikan terapi murottal Al- Qur'an maka diperoleh nilai $\mathrm{p}=0.001$ yang berarti Ho ditolak dan $\mathrm{Ha}$ diterima. Dengan demikian terapi murottal dapat memberikan pengaruh terhadap tingkatkecemasan

Hasil penelitian ini sejalan dengan yang dilakukan oleh Isty Arnita (2014) di RS. Abdoel Moeoloek Padang judul pemberian terapi murottal dengan tingkat kecemasan menunjukkan dari 34 orang, dominan mengalami kecemasan ringan setelah diberikan terapi murottal Al-Qur'an diperoleh nilai $\mathrm{p}=0.019$ yang berarti Ho ditolak dan $\mathrm{Ha}$ diterima. Oleh karena itu terapi murottal memberikan pengaruh positif mengenai kecemasan ibu hamil, karena dengan terapi ini kita dapat mendekatkan idiri kita kepada AllahSWT.

Peneliti berasumsi bahwa dalam pemberian murottal Al-Qur'an mempunyai dua point penting, yaitu memiliki irama yang indah dan juga secara psikologis dapat memotivasi serta memberikan semangat dalam menghadapi stres yang sedang dihadapi. Terapi musik memang dapat menurunkan tingkat kecemasan yang dapat terlihat dari menurunnya ketegangan, pernafasan, tekanan darah, nadi (respon fisiologis). Akan tetapi setelah terapi musik selesai dilaksanakan, pasien kembali dihadapkan pada kenyataan stesor yang akan dihadapinya, sehingga rasa cemas kembali meningkat. Bacaan murottal Al-Qur'an sebagai penyembuh penyakit jasmani dan 
rohani suara, intonasi, makna ayat-ayat yang dapat menimbulkan perubahan baik terhadap organ tubuh manusia. Murottal Al- Qur'an mempunyai dua point penting, yaitu memiliki irama yang indah dan juga secara psikologis dapat memotivasi serta memberikan semangat dalam menghadapi stres yang sedang dihadapi. Terapi musik memang dapat menurunkan tingkat kecemasan yang dapat terlihat dari menurunnya ketegangan, pernafasan, tekanan darah, nadi (respon fisiologis). Akan tetapi setelah terapi musik selesai dilaksanakan, pasien kembali dihadapkan pada kenyataan stesor yang akan dihadapinya, sehingga rasa cemas kembali meningkat

\section{KESIMPULAN}

Dari hasil penelitian dilaksanakan pada bulan Maret-Mei 2018 di RSIA Siti Khadijah III Makassar. Jenis penelitian ini adalah pendekatan eksperimen yang bersifat kuantitatif yaitu Quasy Eksperiment maka diperoleh kesimpulan bahwa ada pengaruh pemberian terapi murottal Al- Qur'an terhadap tingkat kecemasan ibu hamil dengan nilai $p=0,000$ yang berarti Ho ditolak dan Haditerima.

\section{DAFTAR PUSTAKA}

1. Saifuddin AB, 2014. Buku Panduan Praktis Pelayanan Kesehatan Maternal dan Neonatal.

Yayasan Bina Pustaka: Jakarta.

2. Bobak, 2013. Buku Ajar Kperawatan Maternitas Edisi 4. Jakarta: EGC.

3. Azzam, 2015. Terapi Murottal Al-Qur'an. Jakarta : Erlangga

4. Arikunto, 2014. Prosedur Penelitian suatu Pendekatan Praktek. Jakarta: PT. Rineka Cipta.

5. Hidayat, A. 2014. Prosedur Penelitian dan Analisa Teknik Data. Yogyakarta: Pustaka Rihana.

6. Manuaba, 2014. Ilmu Kebidanan, Penyakit Kandungan dan Keluarga Berencana untuk Pendidikan Bidan. Edisi Revisi. Jakarta: EGC

7. Mochtar R., 2014. Sinopsis Obstetri, Obstetri Operasi Obstetrisional. Jakarta: EGC 